www.jmscr.igmpublication.org

Impact Factor (SJIF): 6.379

Index Copernicus Value: 79.54

ISSN (e)-2347-176x ISSN (p) 2455-0450

crossrefDOI: https://dx.doi.org/10.18535/jmscr/v6i11.119

Journal Of Medical Science And Clinical Research

IGM Publication

An official Publication of IGM Publication

\title{
Impact of COPD (Chronic Obstructive Pulmonary Disease) on Health Related Quality of Life (HRQOL) - A Cross Sectional Study
}

\author{
Authors \\ Dr T. Bindu MBBS MD, Dr A.D. Nageswari MBBS DTCD MD², Dr K. Lakshmi \\ Preetha $^{3}$, Dr M. Kiruba ${ }^{4}$, Dr H. Peer Mohaideen MBBS ${ }^{5}$, Dr S.A. Krithika ${ }^{6}$ \\ ${ }^{1}$ Associate Professor, ${ }^{2}$ Professor and Head of the Department \\ ${ }^{3,4}$ Final Year MBBS, ${ }^{5}$ Junior Resident, ${ }^{6}$ Senior Resident \\ Department of Respiratory Medicine, Tagore Medical College and Hospital, Rathinamangalam \\ Corresponding Author \\ Dr T.Bindu MBBS MD \\ Address: NO:65, West Mada Street, Thiruvottiyur, Chennai, Pin code: 600019, India \\ Email: k_sathish123@yahoo.com, Contact no: 9841596074/9790852567
}

\begin{abstract}
COPD is associated with airflow limitation which is only partly reversible. Thus the main focus of treatment is on bringing down the severity of symptoms and improving the quality of life in these subset of patients. This study evaluates the quality of life and variables which affect quality of life in COPD patients.

Materials and Methods: Patients with a registered diagnosis of COPD were enrolled and their quality of life assessed using the St George Respiratory Questionaire for COPD (SGRQ-C).Demographic and clinical data recorded. Severity of COPD was assessed by spirometry (GOLD Guidelines).

Results: HRQOL was significantly reduced in patients suffering from COPD. High HRQOL scores (reduced quality of life)had a strong positive correlation with severity of COPD, prolonged duration of illness and degree of dyspnoea.

Conclusion: Quality of life in COPD patients is poor due to chronic symptoms and frequent exacerbations. COPD evaluation should include HRQOL assessment in addition to pulmonary function test so that pulmonary rehabilitation measures and psychosocial interventions can be planned at the earliest to improve the quality of life.

Keywords: Quality of life, $S G R Q-C, C O P D$.
\end{abstract}

\section{Introduction}

COPD is ranked as the third leading cause of death in 2012 affecting 329 million people which is approximately $5 \%$ of the world's population. ${ }^{(1)}$ This disease presents with progressive symptoms and exacerbations thereby having a significant impact on health related quality of life. ${ }^{(2)}$ HRQOL evaluation is mandatory in all COPD patients as it helps in planning medical therapy, behavioural therapy and psychological interventions at the earliest.

\section{Objectives}

1. To assess the quality of life in COPD patients by using SGRQ-C. 
2. To identify disease specific variables which has an impact on quality of life.

\section{Materials and Methods}

100 male patients with a pre-registered diagnosis of COPD attending outpatient section at respiratory medicine department were enrolled in this cross sectional study. Patients who were 1)>40years2) Ex-Smoker/Current Smoker, FEV1/ FVC $<70 \%$ on spirometry and those willing to take part in this study were included. Known cases of chronic medical illness like Hepatic/ Renal disease, psychiatric illness, malignancy which might be a confounding factor interfering with the quality of life were excluded. Clinical and Demographic data recorded. Degree of dyspnoea assessed by MMRC Scale (Modified Medical Research Council). Spirometry with standard calibration performed by a trained technician according to ATS (American Thoracic Society) Guidelines. GOLD Guidelines was used to classify severity of COPD based on spirometry values. ${ }^{(4)}$ HRQOL was evaluated using the SGRQC Questionnaire.

SGRQ-C is a standard self administered brief questionnaire derived from the original version of SGRQ. ${ }^{(5)}$ It contains 40 items which covers three domains: Symptoms, Activity, Impact and a Total score. This questionnaire is scaled between 0-100 with 0 depicting the best HRQOL. Higher the score poorer the quality of life. ${ }^{(6)}$

\section{Statistical Analysis}

Analysed using SPSS-Version 21 (Statistical Package For Social Sciences) and a $\mathrm{P}$ value of $<0.05$ was said to be significant. Chi- Square test was used to compare categorical data.

\section{Working Definitions}

\section{a) Socio-economic status:}

- $<5000 /$ month - low income

-5000-10000/month - middle income

- >10000/month - high income

b) Education ${ }^{(7)}$

- Illiterate - Not been to school
- Prim. $<10$ th std

- High school - 10th std and above

c) MMRC-Scale for Dyspnoea ${ }^{(8)}$

Grade Symptom complex

$0 \quad$ I only get breathless with strenuous exercise

1 I get short of breath when hurrying on level ground or walking up a slight hill

2 On level ground, I walk slower than people of the same age because of breathlessness, or I have to stop for breath when walking at my own pace on the level

3 I stop for breath after walking about 100 metres or after a few minutes on level ground

4 I am too breathless to leave the house or I am breathless when dressing or undressing

d) Spirometry Findings. ${ }^{(9)}$

\section{Gold guidelines:}

FEV1/FVC- $<70 \%$ and

FEV1 $>80 \%$ - Mild obstruction

$50-79 \%$ - Moderate obstruction

$30-49 \%$ - Severe obstruction

$<30 \%$ - Very Severe obstruction

\section{Results}

Mean age of the study population was $58.7+/-$ 9.1.Demographic and clinical data is depicted in Table-1 and Table-2 respectively.57\% patients were below 55 years and only $24 \%$ had been to high school.43\% had breathlessness for $>10$ years and $77 \%$ had dyspnoea of grade 2-3 (MMRC Scale).

Spirometry values showed that approximately $43 \%$ had severe to very severe obstruction as per GOLD Guidelines (Table: 3). HRQOL Score showed a significant decrease in quality of life in these patients in all the three domains.(Table:4) Variables which had a significant correlation with poor quality of life include increased severity of dyspnoea ( $p$ value-0.002), prolonged duration of illness ( $p$ value- 0.008 ) and increased severity of COPD(p value-0.005) (Table-5) 
Table: 1 Demographic Data

\begin{tabular}{|l|l|c|}
\hline S.No & Variables & $(\mathbf{n = 1 0 0}) \mathbf{( \% )}$ \\
\hline 1. & Age: & $57 \%$ \\
& $<55 \mathrm{yrs}$ & $43 \%$ \\
\hline 2. & 55 yrs & $32 \%$ \\
& Education: & $44 \%$ \\
& Illetrate & $24 \%$ \\
\hline 3. & Primary School & High School \\
& Socio Economic Status: & $56 \%$ \\
& Low & $42 \%$ \\
& Middle & $2 \%$ \\
\hline
\end{tabular}

Table: 2 Clinical Data

\begin{tabular}{|l|l|c|}
\hline S.No & Variables & $(\mathbf{n = 1 0 0 )} \mathbf{( \% )}$ \\
\hline 1. & Duration of Symptoms: & \\
& \multicolumn{1}{|c|}{$>10 \mathrm{yrs}$} & $57 \%$ \\
& \multicolumn{1}{|c|}{ yrs } & $43 \%$ \\
\hline 2. & Degree of Dyspnoea & \\
& (MMRC-Grade) & Nil \\
& 0 & $23 \%$ \\
& 1 & $46 \%$ \\
& 2 & $31 \%$ \\
& 3 & Nil \\
\hline
\end{tabular}

Table: 3 Spirometry Grading (GOLD Guidelines)

\begin{tabular}{|c|c|}
\hline Variables & $(\mathbf{n = 1 0 0 )} \mathbf{( \% )}$ \\
\hline Spirometry (GOLD - Staging) & $24 \%$ \\
Mild & $42 \%$ \\
Moderate & $33 \%$ \\
Severe & $10 \%$ \\
Very Severe & \\
\hline
\end{tabular}

Table: 4 SGRQ-C (Quality of life) Scores in COPD Patients

\begin{tabular}{|l|c|c|c|c|}
\hline & Symptom Score & Activity Score & Impact Score & Total Score \\
\hline Mean & 58.56 & 51.47 & 43.33 & 47.69 \\
\hline Standard Deviation & 37.84 & 33.81 & 30.18 & 34.06 \\
\hline
\end{tabular}

Table: 5 Correlation of SGRQ-C Scores with Disease Related Variables

\begin{tabular}{|l|c|c|c|c|c|c|c|c|}
\hline & \multicolumn{2}{|c|}{ Symptom Score } & \multicolumn{2}{c|}{ Activity Score } & \multicolumn{2}{c|}{ Impact Score } & \multicolumn{2}{c|}{ Total Score } \\
\hline & $\mathbf{X}^{\mathbf{2}}$ & $\mathbf{P}$ value & $\mathbf{X}^{\mathbf{2}}$ & $\mathbf{P}$ value & $\mathbf{X}^{\mathbf{2}}$ & $\mathbf{P}$ value & $\mathbf{X}^{\mathbf{2}}$ & $\mathbf{P}$ value \\
\hline Duration of symptoms & 16.317 & 0.006 & 15.819 & 0.007 & 13.980 & 0.010 & 14.110 & 0.008 \\
\hline Degree of Dyspnoea & 23.104 & 0.001 & 20.126 & 0.002 & 18.680 & 0.005 & 21.620 & 0.002 \\
\hline Spirometry & 52.340 & 0.001 & 48.690 & 0.002 & 41.562 & 0.008 & 46.250 & 0.005 \\
\hline
\end{tabular}

\section{Discussion}

Patients suffering from any chronic medical ailment generally have reduced quality of life and one such entity is COPD. In addition to medical management psychosocial comorbidities needs to be addressed at the earliest as this might lead to increased physical disability and hence reduced quality of life. $^{(9)}$

Reduced quality of life in patients with COPD had been demonstated in many studies conducted worldwide. ${ }^{(2,10-16)}$ Increased degree of dyspnoea and prolonged duration of illness was associated with poor quality of life in our study. Miravitlles et $\mathrm{al}^{(15)}$ and Andenaes et $\mathrm{al}^{(17)}$ had also reported similar findings stating that longer the duration of COPD worse was the quality of life.

Lung function measured by spirometry showed that patients who had severe to very severe grade of COPD had poor quality of life. Dignani et all ${ }^{(18)}$ had reported worsening quality of life in advanced 
stages of COPD. Advanced age, poor socioeconomic status and low educational qualification were variables which also had an adverse effect on quality of life.

\section{Conclusion}

COPD generally shows minimal improvement in lung function despite proper medical therapy. Our focus should therefore be targeted on improving the quality of life and henceforth the disease burden. Quality of life assessment should be included as a part of multimodality approach along with spirometry and pulmonary rehabilitation measures to improve the overall COPD specific health status.

\section{References}

1. Vos T, Flaxman AD, Naghavi M, Lozano R, Michaud C, Ezzati M, et al. Years lived with disability (YLDs) for 1160 sequelae of 289 diseases and injuries 1990-2010: A systematic analysis for the Global Burden of Disease Study 2010. Lancet. 2012;380:2163-96. [PubMed]

2. Jones PW, Prince M, Wijkstra PJ, Patel V, Saxena S, Maj M, et al. Quality of life in patients with chronic obstructive pulmonary disease. Eur Respir Mon. 2006; 38:375-86.

3. Hawthorne G, Richardson J, Osborne R. The Assessment of Quality of Life (AQoL) instrument: A psychometric measure of health-related quality of life. Qual Life Res.1999;8:209-24. [PubMed]

4. Miller MR, Hankinson J, Brusasco V, Burgos F, Casaburi R, Coates A, et al. Standardization of spirometry. Eur Respir J 2005;26:319-38.

5. Schünemann HJ, Griffith L, Jaeschke R, Goldstein R, Stubbing D, Austin P, et al. A comparison of the original chronic respiratory questionnaire with a standardized version. Chest.2003;124:14219. [PubMed)
6. Jones PW, Forde Y. Division of Cardiac and Vascular Science. UK: St George's, University of London; [Last accessed on 2013 Mar 10]. St George's Respiratory Questionnaire for COPD Patients (SGRQC) Manual 2008. Available from: http://www.healthstatus.sgul.ac.uk/SGRQ_ download/SGRQ-

C\%20Manual\%202008.p

7. Lung function impairment in women exposed to biomass fuels during cooking compared to cleaner fuels in uttarpradesh, india. Vipin Bihari et al.Journal of environmental biology. 2013;34:971-974.

8. Global Initiative for Chronic Obstructive Lung Disease (GOLD) Workshop summary. Am J Respir Crit Care Med. 2001;163:1256-1276.

9. Global Initiative for Chronic Obstructive Lung Disease. Global Strategy for the Diagnosis, Management, and Prevention of Chronic Obstructive Pulmonary Disease [Last accessed on 2014 Jan 14]. Available from: http://www.goldcopd.com .

10. Arne M, Lundin F, Boman G, Janson C, Janson S, Emtner M. Factors associated with good self-rated health and quality of life in subjects with self-reported COPD. Int $\mathrm{J}$ Chron Obstruct Pulmon Dis. 2011;6:511-9. [PMC free article] [PubMed]

11. Tsiligianni I, Kocks J, Tzanakis N, Siafakas N, van der Molen T. Factors that influence disease-specific quality of life or health status in patients with COPD: A review and meta-analysis of Pearson correlations. Prim Care Respir J. 2011; 20:257-68. [PubMed]

12. Ferrer M, Alonso J, Morera J, Marrades RM, Khalaf A, Aguar MC, et al. Chronic obstructive pulmonary disease stage and health-related quality of life: The Quality of Life of Chronic Obstructive Pulmonary Disease Study Group. Ann Intern Med. 1997;127:1072-9.[PubMed] 
13. Prigatano GP, Wright EC, Levin D. Quality of life and its predictors in patients with mild hypoxemia and chronic obstructive pulmonary disease. Arch Intern Med. 1984;144:1613-9.[PubMed]

14. Huijsmans RJ, de Haan A, ten Hacken NN, Straver RV, van't Hul AJ. The clinical utility of the GOLD classification of COPD disease severity in pulmonary rehabilitation. Respir Med.2008;102:16271. [PubMed]

15. Miravitlles M, Molina J, Naberan K, Cots JM, Ros F, Llor C. EVOCA study. Factors determining the quality of life of patients with COPD in primary care. Ther Adv Respir Dis.2007;1:85-92. [PubMed]

16. Hajiro T, Nishimura $K$, Tsukino M, Ikeda A, Oga T. Stages of disease severity and factors that affect the health status of patients with chronic obstructive pulmonary disease. Respir Med. 2000; 94:841-6. [PubMed]

17. Andenaes R, Kalfoss MH, Wahl A. Psychological distress and quality of life in hospitalized patients with chronic obstructive pulmonary disease. J Adv Nurs. 2004;46:523-30. [PubMed]

18. Dignani L, Toccaceli A, Lucertini C, Petrucci C, Lancia L. Sleep and quality of life in people with COPD: A descriptivecorrelational study. Clin Nurs Res. 2015 Epub ahead of print. [PubMed]. 